\title{
Student and Teachers Perspective on Cyber-Bullying
}

Umesh $\mathbf{B}^{1^{*}}$, Ali NN ${ }^{1}$, Farzana $\mathbf{R}^{1}$, Bindal $\mathbf{P}^{2}$ and Aminath $\mathbf{N N}^{1}$

${ }^{1}$ School of Medicine, Taylor's University, Lakeside Campus, Subang Jaya, Selangor, Malaysia

${ }^{2}$ School of Dentistry, MAHSA University, Saujana Putra, Selangor, Malaysia

"Corresponding Author: Umesh Bindal, School of Medicine, Taylor's University, Lakeside Campus, Subang Jaya, Selangor, Malaysia, Tel: +60166167582; E-mail: drumeshbindal73@gmail.com

Received date: January 27, 2018, Accepted date: February 06, 2018, Published date: February 09, 2018

Copyright: (c) 2018 Umesh B, et al. This is an open-access article distributed under the terms of the Creative Commons Attribution License, which permits unrestricted use, distribution, and reproduction in any medium, provided the original author and source are credited.

\section{Abstract}

Aim and Objective: Cyber bullying is modern day variant of bullying that has unambiguously taken over the world through the means of technology. This study aims to investigate the context of cyber bullying from the viewpoints of students and teachers respectively. As well as, the related matter which encompasses the measures taken to reduce cyber bullying and the psychosocial aspect of it.

Methodology: The sampling method used for this study was random sampling. In like manner, Google survey forms were prepared with unique set of questions for Students and Teachers. Students were randomly chosen from universities as well as Teachers, to conduct the survey. Furthermore, a series of statistical tests were instrumented to analyse association and validate proposed hypotheses. Chi-square tests and odds ratio were the prominent statistical approach used to justify the proposed hypotheses.

Results: A total of 230 students participated in the students' perspective of the study. Comparatively, 61\% (140) participants have experienced a form of cyber bullying. Furthermore, the study reflected that gender is associated with the likelihood of being cyber-bullied. Spreading rumors over social media remains the most prevalent forms of cyber bullying, at a spike of $43.90 \%$ (101). Correspondingly, the study proved that males were less likely to be Cyber-bullied than females. Also, the study involved 72 teachers who participated in the teachers' perspective of the study. $77 \%$ of the participants complied that students never approach teachers on matters related with cyberbullying. The results indicating doubtful support plans for cyber-bullying on campus, there was an association with the increase of cyber-bullying on campus with frail support facilities against cyber-bullying.

Keywords: Cyber-bullying; Cyber-bullicide; Google; YouTube

\section{Introduction}

Cyber-bullying is a contemporary pandemic, a crime known to be associated with the use of technology. The result of lack of awareness and fitting measures against this strain of harassment among the population has led to an upsurge of victim count today. Technology infuses our daily lives and it is a connected contemporary world today. Gone are the days of sending pigeon mail spanning miles across the country has evolved into sending emails within a fraction of a second. On the other hand, the transparent lives we are living in the contemporary world are an open window to the likes of predators praying for an opportunity to reap? Hacking of your personal social media pages, stealing your information, and to even impersonating as someone, the possibilities are infinite for those committing crimes behind a monitor. In addition, the nature of approach of this variant of bullying often forces victims to face distressing and deplorable consequences. It is claimed that cyber-bullying is the pioneer behind the frequent cases of psychological stress such as depression, and anxiety among victims. In a similar light, this study aims to explore how strongly students studying in the university level understand Cyber-bullying, and the related matters. The study further aims to analyse the perspective of cyber-bullying among teachers and the relevant measures, which may be built to reduce this cause.

\section{Literature Review}

\section{Emergence of cyber-bullying}

The contemporary world we live today boasts an era of prominent access to technology not only at work, but also in our daily household. Most of our time in a day circulates through the means of sending and receiving signals and data from cellphones, laptops or even consoles. Similarly, our cyber-wired world is where each and every one of our lives is intertwined together like a tightly knit ball of wool. Albeit the prodigious advantages conceived by the integration of the cyber-world, something darker rears its head to claw its way into the lives of vulnerable users.

\section{Rationale of cyber-bullying}

Being bullied is something many of us dread from the very first steps our schooling lives. United Nations Education, Scientific, and Cultural Organization (UNESCO) coins the term bullying as a person who gets repetitively harassed negatively by one or more persons, and it is inclined majority of the victims have little to no means of defending themselves [1]. However, bullying itself has cultivated with the seeding of technology and fashioned itself into a design which is known as cyber-bullying. It is a practice of bullying that involves indirect approach towards victims by the manipulative use of social applications on various devices such mobile phones, and computers to harass a person. 


\section{Ascent of social media applications}

Additionally, the abundant social applications such as 'Facebook', 'Twitter', and 'ASKfm' are nesting grounds for cyber-bullies. The amount of Facebook users by 2017 accounts to 2072 million [2] and the amount of Twitter users [3] stands at about 350 million users, these monumental numbers shows an expanding user base for these social platform giants with every passing year. With the evident escalating records, users of social platforms are more prone to become victims of cyber-bullying.

\section{Social behavior Impacts in online video games}

Massively multiplayer online games (MMO), or Internet required video games are the pinnacle of video gaming industry in the modern world. Profuse amount of interactions in these competitive video games involves communicating using microphones with the objective of collaborating together for teamwork. Contrary to that, unmonitored voice communication can often lead to violent verbal abuse among the players. A team of researchers strategized a study, which delved into toxic behaviors associated on the competitive gaming turf. The use of offensive language culminated in more than 800,000 matches surveyed by the study, similarly followed closely by verbal abuse and intentional feeding determined above 600,000 matches [4].

\section{Escalation of cyber-bullying in the United States}

Furthermore a recent study from the United States in October 2016 exhibited that $33.8 \%$ of 5,707 students aged $12-17$ were victimized by cyber-bullying in their lifetime. Likewise, $11.5 \%$ of the 5,707 students confessed they had involved in cyber-bullying others [5]. With such facts establishing an alarming rise in this dreadful act, the question raised is why cyber-bullying remains in the shadow of many other crimes. In a similar light, the cyber-bullying Research Center asserts that females, particularly teenage girls are more prone to experience cyber-bullying than males. The statistics was registered at $25.8 \%$ to $16 \%$ for gender based cyber-bullying [6].

\section{Controversy between free speech and cyber-bullying}

Certain activists spawn controversies that freedom of speech devised from the First Amendment protects mean speech. In July 25th 2009, Katherine Evans from a Miami school posted a disrespectful comment about her teacher Sarah Phelps that resulted in her earning a suspension for cyber-bullying. However, Evans preferred to sue her former principal for being unlawfully charged. Hence, this further supports that cyber-bullying is not established under the legislatures which leads to perpetrators of cyber-bullying to cause mayhem without fear of being prosecuted [6]. The lack of proper regulation of the digital rights of an individual who uses the cyber-world can most often lead to detrimental outcomes.

\section{Parent supervision on children's online activities}

A study demonstrated that the bulk of the cyber-bully victims are teenagers, frequently peaking at the ages of 15 and 16 years old [7]. Likewise, the same study bespeaks of the likelihood of parents being attentive of websites or social platforms their children go online on. In fact, there is a steep decline in the awareness of parents understanding of kid's social activities from ages 10 onwards, and declines even more beyond the ages following 15 [7]. It is a result of a concoction between parents assuming they know what their kids do online, and with age the children grow smarter in finding ways to keep parents away from their own activities too.

\section{Conflicts with parental supervision of online activity}

Parental supervision can often strain the relationship between them and their children. As growing teens are protective over their online activity and personal lives, when they will feel threatened by parents they will be less likely to share with their family about their online interactions. Explicitly, lead to distrust when being spied upon. With this on mind, parents are advised not to spy on their kids, and it will excel more if a parent takes the time to get to understand a child by making the time and effort to get to know them to learn about what is going on in their lives [6].

\section{Psychological and physical impacts of cyber-bullying}

Victims of cyber-bullying are often constrained into a corner where they are no longer able to make a stand for themselves. Namely, this regularly happens under the nose of parents and teachers who are oblivious to the position of the victim. An article on US National Library of Medicine indicated that the phrase 'cyber-bullicide' is materialized when cyber-bullying bluntly or vaguely leads to suicide. Consequently, a survey of 2000 students from secondary grade proved that they were two times more likely to suicide following victimization of cyber-bullying [8]. Many of whom are fueled in their pro-suicide demeanor as an outcome of video influences from websites such as the phenomenal giant, 'YouTube, where certain broadcasters normalize self-harm. Also, unmonitored message boards publicize on ways you can suicide. The synergy established between cyber-bullying and a prosuicide movement claims the eventual death of many victims.

\section{Online advocacy against cyber-bullying}

In the recent times, support groups, and advocacy movements were launched on the Internet. For instance, 'eSafety' branch of the Government of Australia is devoted to dueling the hostilities of the cyber-world by raising awareness and provides a helpline for anyone who seeks guidance [9]. Furthermore, StopCyber-bullying.org is an organization under the wing of the United States government, which yields extensive knowledge on Bullying and cyber-bullying to boost awareness for children, parents and teachers as well $[10,11]$. It is complete with an active social media access and encourages individuals to report cyber-bullying to respective organizations. Although there are such websites instituted for the cause, it is scarce and restricted to the scope of the population it can reach.

\section{Nationwide measures taken to reduce cyber-bullying}

Previous studies brought forth to attention the seriousness of the need to have established laws and legislature against cyber-bullying. Stricter laws can embarrass and slander illegal third party offenders. As a matter of fact, in-grained laws can make people think twice before committing to rash actions online out of anger or even for the purpose of humor. Utter 19 States of the United States of America have constituted cyber-bullying into their legislature [6].

\section{The role of education in preventing cyber-bullying}

The escalation of young teens going into emotional trauma, dropping grades, and even resorting to 'cyber-bullicide' has garnered the attention of some schools around the world. By all means, teachers 
Page 3 of 6

themselves require having the knowledge and understanding of evolving technology, in order to review the ways bullies can exploit it. Likewise, properly educating parents are fundamental in order to raise the awareness to not underestimate the potential threats their growing children may face when using such technology. Teaching children about cyber-bullying, why they shouldn't walk that path, and how to manage them if they face any similar situation [6].

\section{Impact of school policies on cyber-bullying}

It is said that one of the prominent causes of the bloom in cyberbullying among students is because of the lenient school policies. More aggressive responses to schools against cyber-bullies such as suspension and even expulsion may set a benchmark for students not to cross when it comes to using technology. The cyber-world being a land of anonymity can cause students to exploit it over physical bullying knowing that there will be nothing to be concerned of. Notably, Jeanne Kohl-Welles, a legislator received a letter from a distressed mother with daughter who was a victim of cyber-bullying [6]. Unfortunately for her, the District School closed the door on her case, as well as the report to police. Significantly, this is the extent at which cyber-bullying is underestimated for its potential to create emotional and psychological stress. The soaring incidence of cyber bullying from reports upholds the fact that there is much to be executed for this cause by both government bodies, and individuals alike.

\section{Methodology}

The study involves the compilation of data obtained from students studying at university or college level and teachers teaching at college. Two questionnaires were prepared for each respective study group; students and teachers. The questionnaire for students was at an absolute total of 13 questions. Likewise, the questionnaire for teachers consisted of 11 questions. The survey questionnaires were fashioned on Google Forms and the primary language was English. Questions penned for the questionnaire were determined from studies on cyberBullying and other research conducted by professionals. Each survey forms ensure to protect the participant's privacy and personal identification.

The groundwork research questions articulated drafted for the study were:

- There is an association between gender and likelihood of being cyber-bullied.

- Women are more likely to be a victim of cyber-bullying than men.

- There is an association between sharing with family about online interactions and the likelihood of being cyber-bullied.

- There is an association between confidence in anti-cyber-bullying support facilities in a college and the incidence of being cyberbullied.

To validate these hypotheses, 2-tailed Pearson's Chi-Square tests were performed. And the alpha-significance value was 0.05 . If an obtained P-value is less than 0.05 , the alternate hypothesis will be accepted and the null hypothesis will be rejected.

Odds ratio was performed for Alternate Hypothesis 2.

\section{Results and Discussion}

The two perspectives of the study will be portrayed in two subsections.

A. Students perspective on cyber-bullying: 230 responses were recorded and 52\% were males and $48 \%$ were female students.

- Have you been cyber-bullied before or witnessed cyber-bullying? $39 \%$ denied and $61 \%$ says yes

- Have you ever bullied someone using the internet/technology? $8 \%$ said yes and $92 \%$ denied.

- Do you agree that cyber-bullying is more threatening than physical bullying (in-person)? 26\% were neutral, 53\% disagree and 26\% agree.

- Which of the following forms of cyber-bullying have you witnessed or encountered online? 43\% witnesses spreading rumors, Threatening/Flaming in chats $12.60 \%$, posting of private photos online $13.90 \%$, impersonating identity of you or someone else $16.10 \%$, No encounter $36.10 \%$.

- In which application of the Internet did you encounter or witness cyber-bullying? Instant Messaging Apps 19\%, online video games $4 \%$, Social Media Apps 33\%, Forums or Bulletins 29\%, No encounter $35 \%$.

- What actions did you/will you take if you encounter cyberbullying? Change privacy options $44 \%$, Reduce internet usage $14 \%$, Report to family or authority's $12 \%$, do nothing $29 \%$, other $1 \%$.

- How does being cyber-bullied make you feel? Feeling sad or depressed overtime 8\%, Anger towards you or others 1\%, Feeling frustrated $31 \%$, you don't care $23 \%$, did not encounter cyberbullying $37 \%$.

- Do you share with your family who you interact online with? Yes $9 \%$, No $68 \%$, Sometimes and $23 \%$.

- Does your household enforce any parental control over the internet? No $87 \%$, Yes $13 \%$.

- On a scale 1-10, how serious do you think cyber-bullying has become as a crime today? Over $90 \%$ were above the scale of 5 and $3.90 \%$ rated it to be 10 the most serious.

- Cyber-bullying is not a federal offense in many nations. Do you think cyber-bullying should be considered as a federal offense in more nations around the world? Yes $92 \%$, No $8 \%$.

- What do you think is the most important action society can implement to reduce cyber-bullying? Majority (54.8\%) were in the favor of federal law to punish.

B. Teachers perspective on cyber-bullying: 72 responses were recorded.

- How often do students approach you about being cyber-bullied? $76.4 \%$ never approach and $22 \%$ approach sometime.

- Do you agree cyber-bullying is more threatening than physical bullying? 55.6\% were neutral and 36.6\% disagree.

- Did you participate or organize any cyber-bullying awareness campaign at your university/college? $98.5 \%$ never participated in any campaign.

- Why do you think perpetrators of cyber-bullying are able to victimize students? $41.70 \%$ think the lack of control over student's access to internet/technology, 30.60\% Lack of proper support and awareness for students, $20.8 \%$ because many students are sensitive, $6.90 \%$ feels there are no rules and regulation against cyber-bullying at the facility. 
Page 4 of 6

- How common is cyber-bullying at your education facility? $2 \%$ responded for the common occurrence, $47 \%$ never encountered, and $36 \%$ rare, $15 \%$ uncommon.

- Do you agree that cyber-bullying is protected by freedom of speech? 28\% Agree, 36\% Disagree, 36\% Neutral.

- Does your education facility enforce any official rule against cyberbullying? $67 \%$ No, $32 \%$ Not certain, Yes $1 \%$.

- Are you confident students able to seek proper support for cyberbullying at your education facility? 39\% Not certain, 33\% Needs improvement, 25\% Unconfident, 3\% Confident.

- How can education institutions reduce cyber-bullying? $43.10 \%$ implementing proper support groups and counseling for students, $29.20 \%$ campaigns to raise awareness, Enforcing rules and punishments $21.70 \%$.

- Do you agree that cyber-bullying help students face the harsher real world? $91.7 \%$ agreed.

\section{Students perspective of cyber-bullying}

Nearly $61 \%$ (140 participants) out of the 230 participants has faced or witnessed cyber-bullying. Similarly, Chi-square test was performed to determine if gender played a role in being cyber-bullied. The results revealed a P-value $<0.05(0.000)$ which is statistically significant and emphasizes a strong association. The alternate hypothesis (H1) stating that gender is associated with the likelihood of being cyber-bullied is accepted. In fact, similar results have been reflected as discussed in the literature review (2.5 Escalation of cyber-bullying in the united states) where females were more prone to be victimized.

Furthermore, the odds of the type of gender at risk of cyber-bullying were strategized in Table 1. It was observed that men had 0.278 times less likelihood of being Cyber-bullied than women. Contrary to that, women were 3.60 times more likely to be Cyber-bullied compared to men. Thus, the hypothesis (H2), which asserts that women are more likely to be cyber-bullied, is accepted. Clearly, the obtained odds ratio significantly supports the hypothesis (H1) and the fact women are more vulnerable for being cyber-bullied as mentioned in $(2.5$ Escalation of cyber-bullying in the united states).

\begin{tabular}{|l|l|l|l|}
\hline \multicolumn{2}{|l|}{ Risk Estimate } & & \multicolumn{2}{l|}{$95 \%$ Confidence interval } \\
\cline { 2 - 5 } & Value & Lower & Upper \\
\hline Odds ratio for gender of participants (Male/Female) & 0.278 & 0.159 & 0.485 \\
\hline For cohort have you been cyber-bullied before? = Yes & 0.606 & 0.482 & 0.762 \\
\hline For cohort have you been cyber-bullied before? = No & 2.182 & 1.532 & 3.108 \\
\hline N of valid cases & 230 & & \\
\hline
\end{tabular}

Table 1: Odds ratio of gender and being cyber-bullied.

In addition, Chi-Square test performed with a P-value $<0.05(0.011)$ which is statistically significant. As a result, the hypothesis (H3) stating there is an association between sharing of online interaction with family and the likelihood of being Cyber-bullied is accepted. As an individual's family grows more aware of their online interactions, there will be greater chance for the family to advice against suspicious online activities to prevent harassment from a Cyber bully.

\section{The Social and Behavioral Aspect}

The Figure 1 expresses that Social Media applications (33\%; 75) peaks as the most prevalent field where cyber-bullying thrives. It is fair to say that many of the participants in the universities and colleges actively use the social media on a daily basis. Clearly, the literature review (2.3 Ascent of Social Media) implies that with the growth of monumental social media giants, people are likely to exploit it for cyber-bullying others. The large pool of users using social media giants will pave the way for cyber bullies to have higher freedom in picking their targets. Not only that, social media websites are accessible with a tap of a finger which makes it an ideal tool for harassment at the leisure of the cyber-bully. As result, iconic social media websites remain as the pinnacle in cyber-bullying attacks. The most frequently exhibited form of cyber-bullying is indicated as spreading of rumors, which is $43.90 \%$; 101. Social media applications as discussed earlier could play a pivotal ideal role in making it achievable (Paragraph 1, 5.1.2 The Social Aspect) because such websites allows the spread of information to a large pool of users within a fraction of a second. Rumors are commonly heard on campus grounds, alongside gossip. However, it becomes threatening in nature when such rumors are directed to hurt the feelings of a person. Spreading rumors through digital means is easier than ever having social media websites downloaded on our phones in our day to day lives.

Threatening and flaming although not dominantly large, makes it presence in $(12.60 \% ; 29)$ certain competitive games are notorious for threatening and flaming in chats as mentioned in the literature review (2.4 Social Behavior Impacts in Online Video Games). For example, it is frequently seen in popular video games such 'DotA', and 'League of Legends'. Rules are often established in these games against it; however it is often the result of extreme frustration from losing a match or annoyance within game leading players to release their anger on their fellow gamers.

As a matter of fact, $87 \%$ (200) of the participants claim their household does not enforce any form of parental control. Undoubtedly, the literature review (2.7 Parents supervision of children's online activities) highlights that most parents underestimates the possibilities of their children being victimized by Cyber-bullying. Henceforth, 
Page 5 of 6

ignorance may induce parents to feel little to no need in emphasizing parental controls in the household.

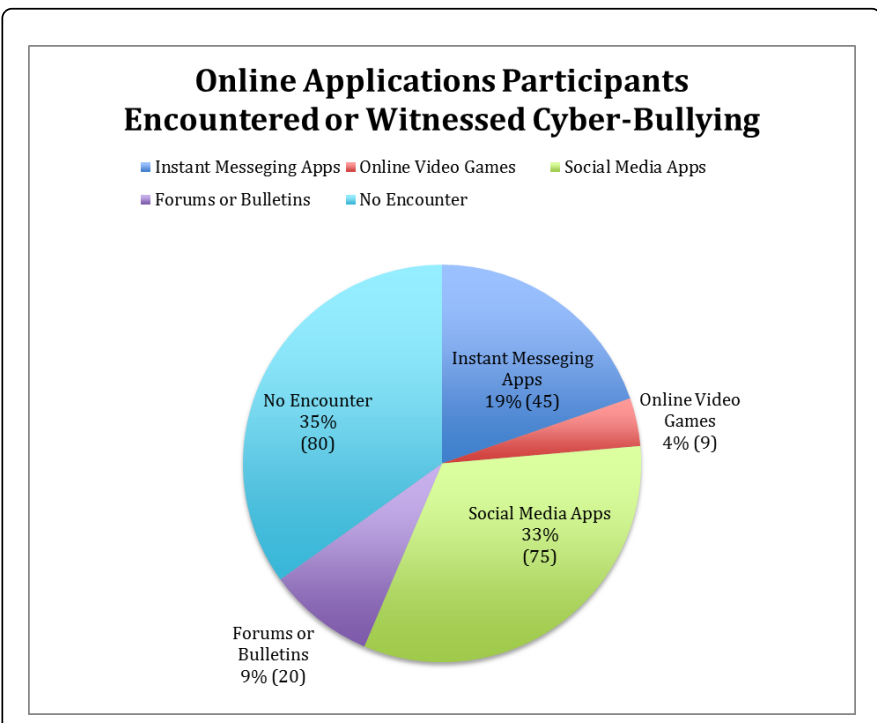

Figure 1: Online applications of participants.

In the same fashion, bulk of the respondents claimed to not share whom they interact online with their family $(68 \% ; 156)$. Growing young adults and teenagers alike prefers privacy as reflected in (2.7.i Conflicts with Parental Supervision of Online Activity) due to parents often taking a less understanding approach when dealing with a child's personal matter. Eventually, this leads to distrust in sharing about the child's personal life with a family member. On the other hand, such distrust lowers the guard and in turn allows them to be marked by digital predators easily. As previously discussed in the analysis of alternate hypothesis (H3), sharing with family members can help reduce the likelihood of being cyber-bullied. In light of it all, a large number of participants remark that the action they will take for cyberbullying will be changing privacy options (44\%; 98). Many growing teens may not be aware of extensive privacy features and the possibility to become the hunted for a prying cyber bully. This is coherently linked to (2.5 Escalation of Cyber-Bullying in the United States) where the large number cyber-bullying victims are on the rise, and could be a result of poor privacy settings causing young users to expose their personal details online to possible threats. Most individuals learn about privacy options as they grow older or from experience and thus today, many young adults using social media will turn to privacy options to control who can read their feeds online.

\section{The Psychological Aspect}

A significantly large number of respondents felt frustrated from cyber-bullying ( $31 \% ; 72)$. To enumerate, high levels of frustration can make person more vulnerable to self-harm and suicidal thoughts. Intensive levels of suicidal thoughts are known to compose suicidal demeanor as remarked in (2.8 Psychological and Physical Impacts of cyber-bullying). It is not abnormal to feel stressed out when someone online threatens you with your own personal information, or even photographs because there will be the consistent worry of these information being used against the victims. Likewise, such frustrations are also known to alienate victims from their studies, or chores. Majority of the respondents believe that cyber-bullying is slightly above the mediocre level of seriousness as a threat (Peaks at seriousness level of $7,31.30 \%, 72$ ). In spite of the general trend leaning to a more serious outlook on Cyber-bullying, a large number of individuals do not find cyber-bullying as threatening as its physical counterpart $(53 \% ; 122)$. It is natural we tend to fear physical harassment, and the embarrassment that follows during bullying in front of a crowd of students. However, cyber-bullying happens behind a screen of a device where the bully does not expose himself or herself, and the victim can be at the comfort of their own home when the bullying occurs. Obviously, the latter sounds less threatening because the victim assumes they have more control over the situation in contrast to being physically bullied.

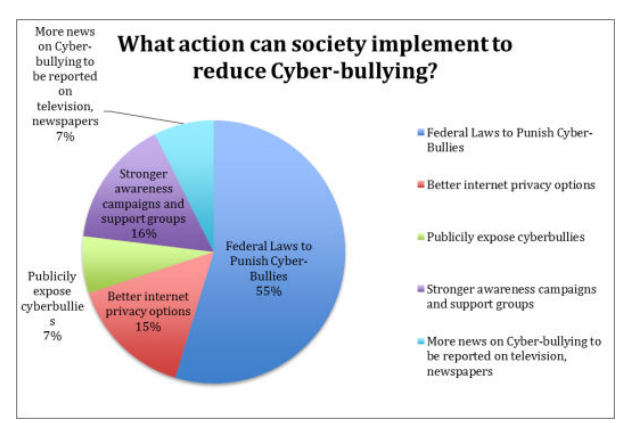

Figure 2: Proposed action by the society.

A substantial amount of participants (92\%; 211) wants cyberbullying deemed as a federal offense nationwide. Only few nations in this world deem cyber-bullying as federal offense. Even in the text (2.9.i nationwide measures taken to reduce cyber-bullying) validates that only a handful of states in United States alone identifies Cyberbullying as a crime. Nearly $55 \%$ in (Figure 2) of the participants believe that implementing federal rules will help reduce incidences of cyberbullying that further emphasizes what has been discussed in 2.9.i. Following the implementation of government rules, cyber bullies will be less likely to take their own risk and chase a victim. Having ways to identify cyber bullies, and prosecuting them will not only provide justice for victims, but also educate future cyber bullies about this hideous crime.

\section{Teachers Perspective of Cyber-Bullying}

A chi-square test established to analyze the possibility of an association between current facilities offered at an education facility to help cyber-bullying victims and known occurrence of cyber-bullying on campus according to teachers. The achieved $\mathrm{P}$-value was $\mathrm{P}<0.05$ $(0.022)$ and thus the results were significant. As a result, the proposed alternate hypothesis (H4) is accepted, where there is an association between the facilities for cyber-bullying victims in an education institution and occurrence of cyber-bullying victims. The literature section (2.9 Online Advocacy Against cyber-bullying) places emphasis on the prodigious importance of having accessible helplines and support for victims. Undoubtedly, implementing such support systems can reach out to more victims on campus as well as being a pillar of awareness for others. Educating counselors on cyber-bullying will also establish better communication between a cyber-bully victim and the counselor. This will help counselors to establish better programs targeted for digital security, awareness and support for all students. 
Page 6 of 6

Majority (96\%) of teachers did not involve in any event against cyber-bullying. On a similar note, it highlights (2.9.ii Role of Education In cyber-bullying) where educating teachers on cyber-bullying is vital. Teaching should not orbit only around the fixed subjects but it should also involve teaching about lifestyle, environments and also the digital world as it has grasped a great deal of our lives today. If teachers remain uneducated about cyber-bullying, they will be unaware when a student who is unfortunate to face this pummels in their studies. Hence it is crucial schools organize events for cyber-bullying targeting not only students but teachers as well. Most teachers $(41.70 \% ; 30)$ believe that uncontrolled access is the main reason student fall victims to cyber-bullying. For instance, to regulate school networks as mentioned in (2.9.iii Impact of school policies on cyber-Bullying) may reduce similar occurrence of cyber-bullying. Internet is a huge world of its own, and unmonitored access often can lead students to stroll into malicious websites of many forms. For instance, a 'phishing website' disguised as trustworthy website. But, as you key in your personal log in details or other information, the 'phishing website' will capture these data and use it to access your information instead. Frequently, the victim will not be aware they unknowingly gave their information to a phishing website until it is too late. And hence, restricting certain suspicious websites on networks is a start in reducing cyber-bullies.

Identically, 47\%; 34 of the teachers never encountered cyberbullying. Such statistical data may depict the lack of awareness on cyber-bullying among teachers that is in light with (2.9.ii Role of Education In Cyber-bullying), which could be due to lack of awareness on cyber-bullying. However, it can also be due to unwilling nature of students to share with teachers that they are being cyber-bullied. Possibly it could be due to distrust, or they may judge the ability for the teacher to help their situation. Similarly, this is closely related to why students may not share their personal issues with their family as mentioned in (2.7.i Conflicts with Parental Supervision of Online Activity).

An equal number of participants disagrees and remain neutral about the fact that cyber-bullying is protected by freedom of speech. With this in mind, it contradicts the statements made in (2.6 Controversy between Free Speech and Cyber-Bullying). In contrast, it is viable that participants made the assumption boundless free speech do not include crude words or remarks. However, this is not entirely right as free speech does include any form of comment. Freedom of speech is the principle by which a person can express themselves with words without any restrictions. Yet, many are quick to assume hateful words are wrong, but they do go hand in hand with freedom of speech. Moreover, most of the respondents $(43.10 \%$; 31$)$ consider implementing support groups and counseling for cyber-bullying victims. Perhaps providing easier accessible means of help such as hotlines for cyber-bullying from a trustable counselor on campus or as respondents as mentioned in (2.9 Online Advocacy Against cyberbullying) may support students to open up. It was previously discussed that students are less likely to open to family or teachers; hence, having someone they can look for when they need positive advices is crucial. Particularly, in extreme cases of cyber-bullying students are often forced to feel that they are worthless, or their dignity is lost. Having a support group offers the chance for victims to meet others who may have similar experiences, and thus can be a learning experience to build upon. Similar sessions can help victims to love their own self again following the aftermath of cyber-bullying. Equally important in is teaching about proper Internet etiquette and safety measures, which peaks at about $(21.70 \% ; 21)$. It explicitly demonstrates the crucial necessity of education on cyber security as discussed in (2.9.ii Role of Education In cyber-bullying). Educating on using Internet privacy options, how to protect personal information and to identify fake websites (such as phishing websites) can help a great deal of students, teachers as well as parents. In a similar light, it can help raise awareness of the impact digital harassment and other threats can cause to an individual. Not only knowing, but applying this knowledge in our day to day lives remains essential because we use our devices every day.

\section{Limitations}

The most considerable limitation was the time of the year this study took place in. December is the time of the year where holidays unfold and teachers, as well as students move out of campus for their hometowns. The target sample size for this study was 200 teachers. However, only 72 participants were achieved for the teachers' perspective due to majority of the teachers being on holiday leave.

Lastly, online distribution of the survey forms proved that few participants responded to the study. In particular, among 80 survey forms that were distributed to students, only around 20 students responded to the survey, which was a poor response rate. Thus, personally distributing the survey in person was more efficient.

\section{Conclusion}

Evident facts from this study have proven that cyber-bullying continues to remain as a strong growing force in the contemporary generation. Notably, cyber-bullying remains underestimated due to poor emphasis placed on the importance of understanding this crime as observed in the teachers' Perspective of the study. As a result, coupled with the lack of awareness, support systems and also poor policies against cyber-bullying in education facilities, students are more prone to become subjected to this digital crime as depicted with the high percentage of victims. Ultimately, enforcing robust rules, enacting firm support groups and awareness projects may assist in reducing cyber-bullying among students. As of now cyber-bullying is a felony that struggles to find its limelight as a pandemic threat.

\section{References}

1. Dan O (1993) Definition of bullying, United Nations Educational, Scientific and Cultural Organization, UK.

2. Facebook users worldwide 2017, Statista, Germany.

3. Twitter: number of active users 2010-2017, Statista, Germany.

4. Kwak H, Doha Q, Blackburn J, Han S (2017) Exploring Cyber-bullying and Other Toxic Behavior in Team Competition Online Games, Cornell University Library, USA.

5. Patchin JW, Hinduja S (2016) Cyber-bullying data, Cyber-bullying Research Center, Georgia.

6. Friedman LS (2011) Cyber-bullying, Gale cengage press, USA.

7. Teens and Cyber-bullying, Executive summary of a report on research, NCPC, US.

8. Luxton DD, June JD, Fairall JM (2012) Social Media and Suicide: A Public Health Perspective. Am J Public Heal 102:195-200.

9. Cyber-bullying (2017) esafety.gov.au, Australia.

10. What Is Cyber-bullying (2017), StopBullying.gov, US.

11. Harassment and bullying prohibited-policy-immunity, Iowa General Assembly, US. 